\title{
Hopefulness and the Mothers' Wellbeing: Children with SpLD
}

\author{
Noor Amiera Alias, Akehsan Dahlan, \\ Azliyana Azizan \\ Faculty of Health Sciences, \\ University Technology MARA, Malaysia \\ nooramiera@puncakalam.uitm.edu.my
}

\begin{abstract}
Mothers who are having children with SpLD may have changes in their hopes since they may experience many dramatic changes in life circumstances. A semi-structured interview was conducted to explore mother's hopes in providing care children with SpLD. The data was analysed using six stages of the interpretative phenomenological analysis (IPA). The finding revealed that two superordinate themes emerged: "I have faith..." and "I'm expecting..." relating to different perspectives of hopes. A positive hope facilitates positive influence among mothers in providing care children with SpLD. Later, it postulated a better quality of life amongst mother in having children with SpLD.
\end{abstract}

Keywords: Mothers ; Hopes; Spesific Learning Disability

eISSN 2398-4279 @ 2018. The Authors. Published for AMER ABRA cE-Bs by e-International Publishing House, Ltd., UK. This is an open access article under the CC BY-NC-ND license (http://creativecommons.org/licenses/bync-nd/4.0). Peer-review under responsibility of AMER (Association of Malaysian Environment-Behaviour Researchers), ABRA (Association of Behavioural Researchers on Asians) and CE-Bs (Centre for EnvironmentBehaviour Studies), Faculty of Architecture, Planning \& Surveying, Universiti Teknologi MARA, Malaysia.

DOI: https://doi.org/10.21834/ajqol.v3i13.162 


\subsection{Introduction}

The number of enrollment of special education among children with learning difficulties showed increasing from 2010 to 2013 which estimated 50, 738 to 54, 000 (UNICEF, 2014). The numbers are alarming that there is increasing trend of parents or caregivers who may have and taking care children with learning difficulties. Based on UNICEF (2014), learning difficulties category also includes conditions that affect the learning ability of an individual such as Autism, Down syndrome and specific learning difficulties (SpLD) (Dyslexia, dyscalculia and dysgraphia). This study focuses on mothers who are having children with condition SpLD due to there were limited studies highlighted on this condition (Noor Amiera \& Akehsan, 2015).

Commonly, many parents are hoping for their children to be successful in life and live with happiness in society. Parents' hopes may change since they may experience different life circumstances, such as changes in lifestyle, social life, family plans, expectations, different work life and emotional well being as a result of taking care of the children with SpLD. Hope is defined as a root in one's belief, and people act as goal-oriented in the ability to achieve future aims (Ogston, Mackintosh, \& Myers, 2011). Parents who are having children with SpLD may have different hope, and different perception about hopes compare to parents with typical children. Mothers were concerned about the future life of their children including carefree childhoods, employment; continue higher education, social relationships, and married life. Their hopes in certain help them to be more positive in surrounding and becoming an optimist personality in providing care to their children with SpLD.

In fact, it was found that having hope could be a resilience factor for the psychological well-being of caregiver of children with disability (Lloyd \& Hastings, 2009). With hope, they may feel more positive to overcome all challenges and negative feelings in their experience in taking care children with disabilities. This is because they may have increased spiritual growth and motivation to survive to see the hopes become a reality. It was reported that the parents who are having high hope would have less of feeling worried about their children (Ogston et al., 2011). It has been identified as a positive transformation and dynamic process that helps the caregiver to reframe their lives given their experience with children with disabilities Kausar et al. (2003).

\subsection{Literature Review}

According to Kausar et al. (2003) hope was strengthened by both their internal include belief system, motivation and rationality while external includes family and friends resources. They found that parents able to deal with their child's disability when they recognized their inner potential and hidden qualities. Having children with disabilities give them a sense of strength, transcendence, and meaning in life. Negative influences such as the negative attitude of health professionals whereby to result in hopeless feeling about the future life of their children. It shows that hope is to play an important role in parents' life when having children with disabilities.

Previously, Jenaabadi (2014) found that mothers who are having children with disability are more stress compared parents of typical ones. It is may lead to having negative hopes 
which may affect parents' life, while parents who are living with positive hopes may have good health, comfort and happiness experienced. Mothers are also worried about their wellbeing and have maintained their sense of self while feeling worried in dealing with their children and families (Ogston et al., 2011). It is shown that it is important to concern about the mothers' hope related their well being to ensure that the children with disabilities in good care. Despite there were studies done in the area of hope, the nature and function of hope in the area of children with special needs have been neglected in the professional literature (Kausar et al., 2003). To date, limited studies have explored how hopefulness functions in mothers of children with SpLD and how it relates to facets of mothers' well-being. The purpose of the present study was to explore how hopefulness influence and affect the mothers' well being including their higher life satisfaction, less parenting stress, and less depressive symptoms in a meanwhile able to give their optimum level of motivation in providing care children with SpLD. Understanding how this child focused construct relates to mother functioning is vital for bettering the lives of mothers in providing care children with SpLD.

\subsection{Methodology}

This current study was conducted using a phenomenology approach since it is the nature of the qualitative study is it attempts to provide an exploration of one's life experiences (Smith, Flowers \& Larkin, 2009). It is aligned with the aims of this study to obtain further details about mothers' life experiences.

The participants were recruited based on purposive sampling strategy. There were twelve mothers who have a child diagnosed with SpLD participated in this study. The Headquarters of Dyslexia Association Malaysia (DAM), Malaysia was chosen as a setting because it has many mothers who are sending their children with SpLD there. The inclusion to the study are a) The mothers' age range between 30 to 43 years old 2) Mothers held a caring role for children aged between 6 to 12 years old 3) Mothers who get scores 22 and above in Malay-Mini Mental States (MMSE) (Zarina, Zahiruddin, \& Che Wan, 2007) 4) Mothers scores nine and below in the Depression Anxiety Stress Scale (Musa, Fadzil, \& Zain, 2007). Both scores of assessments signified mothers have a good cognitive function and are not depressed. 5) Mothers are having different regarding their education level, personal background and duration of caregiving to the children. This is an endeavour to explore a diverse variety of their unique experiences in providing care children with SpLD.

The interview was carried out in the form of a semi-structured interview by using interview guide consists of open-ended questions (see Appendix A). The interview session occurs for approximately 45 minutes to one hour individually. All conversations were recorded throughout the interview session using an audio recording device. The recorded interviews were subsequently transcribed into verbatim.

The transcripts were closely analyzed using the six steps of Interpretative Phenomenological Analysis (IPA) as described by Smith et al. (2009). Several quotes were selected to represent the emerging themes. To ensure the rigour or trustworthiness of the study, several methods were employed such as no bias was ensured during the construction 
of questions. The pseudonym will be used to illustrate the quotes presented by the participants of the study which aligned with the ethical principle of anonymity and confidentiality.

\subsection{Results}

The finding revealed that two superordinate themes emerged: "I have faith..." relating to sub themes the goals to have improvement and happiness life while "I'm expecting..." relating to sub themes feeling of despair towards their children with learning disability see Table 1.

Table 1. Superordinate Themes and sub themes

\begin{tabular}{|l|l|}
\hline Superordinate theme & Subthemes \\
\hline "I have faith..." & Improvement Happiness life \\
\hline "I'm expecting..." & Feeling of despair \\
\hline
\end{tabular}

"I have faith..."emerged to describe the mothers' having positive hopes towards their children with SpLD in future. This hope is described as their beliefs on a thing that gives them comfort feeling, have the confidence to keep on giving support to their children and able to overcome the sadness of having children with SpLD. There are two subthemes emerged: improvement and happiness life.

\section{Improvement}

Subtheme improvement is developed to describe that most of the mothers claimed that they hope for improvement in facilities such as more centre branches built, or enhance the number of a special school for Learning disability provided in each state in Malaysia. It describes the mothers' hope for better facilities, increasing number of experts in learning disability, enhancing knowledge and awareness and any other sources that can help children with learning disability. It helps the mothers to give their optimum level of effort in taking care of their children. The mother has faith that if there is keep on supporting in term of expertise and excellent facilities, the mother feels that the children can achieve a real achievement in academic performance. Both different mothers, Ms Tasha, have described this:

"When I see a doctor, therapist and they have their full chart of development that say what normal kids should achieve by this age and what should they do at this age)...I hope I can make him to a better person push him to the maximum that he could do with support to be independent for living in the future...I have faith that if we help my son will be able to perform excellently in academic".

\section{Happiness life}

Subtheme happiness life is representing the mothers' hopes that the children can survive on their own in future life. Some of the mothers shared their hopes while making previous successful people as their inspiration. They hope that the child will grow up and make an accomplishment similar to normal children such as studying in a university, live a happy married life and be able to earn money independently. One of the mother describes how 
others successful help them to have higher hope towards their children. They got passion when they read and hear about other's achievement. Moreover, it turns to feeling relieve and less worries about their children. Ms Fify describes it:

"When I read research about the scientist, Albert einstein he also successful. So, from there I got passion and my inspiration a lot. I think my son can do it. Last few days my neighbours got result $5 \mathrm{~A}$ UPSR...its so awesome to hear that. Oh, yeah...Tom cruise is also having learning difficulties too. Can u see how successful

he is...so I feel like "wow"...we should keep supporting them."

The quote showed that positive hopes and expectation help the mothers to have positive thinking and keep on supporting their children to face the journey as children with SpLD.

\section{Feeling of despair}

"I'm expecting..." refer to contrary hopes which mothers feel that their expectation is beyond of their knowledge and thinking. Some of the mothers feeling of despair with their children due to many factors including school rejection, relatives and society perception. They feel devastated when some of the school reject their children and advice them to send their children to special class or special school. This can be illustrated by one of the mothers, Ms Tania:

"She physically looks normal; I'm expecting that she's able to survive without me...some school reject her...but again....we don't know what will happen...I feel so worried... until I hope that she dies before me... not because I didn't love her...but I'm so worried about her...[crying]"

\subsection{Discussion}

This study has presented there are two main superordinate themes emerged: "I have faith..." and "I'm expecting". The analysis yielded two subthemes improvement and happiness life relating to positive hopes that facilitate mothers' well being while subtheme feeling of despair towards children with SpLD emerged in relating to negative hopes.

Improvement is highlighted to mothers' hope related to have improvement of facilities, expertise, knowledge about SpLD which it gives affects towards mothers' hope. It is believed that, if there is an improvement in the highlighted areas, the mothers might increase their motivation in providing care to their children. They may see that their children have a potential to succeed like others. It is agreed that hope for a recovery of their child encourages the determination of mothers to fight and help the children (Oprea \& Stan, 2012). They also play an important role in encouraging their children in learning (Morni \& Sahari, 2013; Yurdakal \& Kirmizi, 2015). Although there is increasing the number of a special class for special needs from year to year, much improvement in facilities and a special class for SpLD are still needed. Such efforts from the government and NGOs may decrease the barriers providing care of children with SpLD and mothers have the ability set and meet goals and continue having hopes towards children (Ogston et al., 2011). It also suggested exposing the mothers with a success story to facilitate the mothers to maintain their positive hopes and get inspired with others successful. Hopeful thinking makes the mothers stronger to cope with challenges, critical thinking to achieve better and to find a creative solution when faced with a difficult situation (Tarhan, Bacanli, Dombayci, \& Demir, 2011). Subsequently, it helps the mothers to sustain their spiritual and high motivation to continue the life journey with their children with 
SpLD.

Happiness life is a description of the mothers who are having higher hope towards their children with SpLD. Having such hope help mother for being optimist towards their own life as well. It helps the mothers to avoid stressful lifestyle and low level of life satisfaction. Mothers who have positive hopes are associated with positive effects in psychological health, which are more likely to make them feel satisfied with their lives and feel better about themselves (Du \& King, 2013). This finding is in agreement with that of Safarzadeh (2012) hopefulness able to develop optimist characteristic and gives a meaning to life. It shows that it is encouraging to mothers to have positive hopes for a well-being life and having a good quality of life. Parents support group with hope- oriented able to improve mothers quality of life (Ghezelseflo \& Esbati, 2013). Through support group program the mothers able to expose with other mothers and exchange their experiences as well as sharing hopes that can help mothers decrease their negative feelings.

Feelings of despair towards their children with SpLD represent that some of the mothers are experienced negative hopes in taking care of their children. Some of the mothers feel that there is no person that is going to replace them in taking care their children. This may due to they hold most of the roles and responsibilities in taking care their children. Consistent with a study done by Kermanshahi et al. (2008), the mothers hoped that the children would die before they did as they were doubtful about the abilities of their children to be independent in their life. The mothers also have been described having irrational social attitudes irrespective of experience of bringing up their children (Kruteleva \& Abakumova, 2015). Some of the mothers in this study described that they have sleep disturbances and low motivation when thinking about their children. As a result, it affects the mothers such as their lifestyles, stressful and anxiety feeling towards their children. This may occur due to the mothers may have lack of knowledge about SpLD. It is supported by Shabas (2016) that parents are having lack of knowledge about their children' individual and age peculiarities lead to adverse effects towards children. It is found that the parents who have gained knowledge showed more understanding and unanimity relative towards their children which can be a protective factor to overcome negative life events (Zakeri, Jowkar, \& Razmjoee, 2010). It has been found that service providers' and professionals' negative evaluations of the child's disability reportedly made parents feel hopeless for the child's future (Kausar et al., 2003). Thus, it is suggested to mothers for exposing more about SpLD conditions, which help the mothers to overcome the negative hope that they have. It is encouraging to fathers joining the mothers and understand the mothers' needs and concerned (Gharibi \& Gholizadeh, 2011). Additionally, increase individual and interpersonal nature help the mothers to have positive thinking towards their children with SpLD. It is has found that believe in God and accept their fate able to be protected factor (Oprea \& Stan, 2012) on mothers in keep supporting their children with SpLD.

The restriction of this study is the use of IPA as a methodology to analyze the data. The potential bias of questions occurs when using a self-involved approach in conducting interviews (Yujin Kim, 2010). However, this study used peer debriefing and member checking methods to minimize any possible bias in the interpretation of the analyzed data. The findings of this study also limit the generalization to mothers who are taking care and sending their 
children to DAM and relatively small sample size. However, the aim of this study is not concerned with generalizing the sample to the broader population, but rather to explore the unique experiences of this group of individuals. This study only recruited mothers while may differ according to the nature of the father's relationship with their children and it is essential to have both genders in the exploration of experiences (Zakeri et al., 2010).

\subsection{Conclusion}

The emphasis on creating hopefulness and expectation of mothers in providing care towards children with SpLD has resulted in a reduction of distress, having meaningful of life, and an increase of tranquillity and energy in them. The mothers who are having children with SpLD should have well-being and a high quality of life to continue taking care and give support to their children in optimum level. High quality and efficient programs begin by identifying the specific issues most detrimental to the parental quality of life, which determines the appropriate intervention for that individual. Noteworthy, health professional such as occupational therapist should concern that future intervention strategies should strive to provide parent and child focused intervention concurrently. Therefore, the mothers can avoid negative psychological suffering. It is also recommended to further study about hopefulness among fathers that may reveal different findings, perspectives and experiences compare to others. Finally, it is important to mothers to have positive hopes in providing care towards their children with SpLD consistent and continue to enable mothers to have a well-being and a high quality of life.

\section{Acknowledgement}

The authors wish to thank the Faculty of Health Sciences, University Teknologi MARA (UiTM). The authors would also like to acknowledge the President and staff at the Dyslexia Association Malaysia and participants in this study.

\section{References}

Du, H., \& King, R. B. (2013). Placing hope in self and others: Exploring the relationships among self-construals, locus of hope, and adjustment. Personality and Individual Differences, 54(3), 332-337.

Gharibi, H., \& Gholizadeh, Z. (2011). Social and Phenomenology of mothers experiences in living with children with AD / HD disorder. Procedia - Social and Behavioral Science, 30, 1630-1634.

Ghezelseflo, M., \& Esbati, M. (2013). Effectiveness of Hope-Oriented Group Therapy on Improving Quality of Life in HIV+ Male Patients. Procedia - Social and Behavioral Sciences, 84, 534-537.

Jenaabadi, H. (2014). The Study and Comparison of Stress Levels and Coping Strategies in Parents of Exceptional (Mentally Retarded, Blind and Deaf) and Normal Children in Zahedan. Procedia - Social and Behavioral Sciences, 114, 197-202. 
Kausar, S., Jevne, R. F., \& Sobsey, D. (2003). Hope in Families of Children with Developmental Disabilities.

Kermanshahi, S. M., Vanaki, Z., Ahmadi, F., Kazemnejad, A., \& Azadfalah, P. (2008). Children with learning disabilities: A phenomenological study of the lived experiences of Iranian mothers. International Journal of Qualitative Studies on Health and Well-Being, 3, 18-26.

Kruteleva, L. J., \& Abakumova, I. V. (2015). Characteristic Features of Sense-value Attitudes of Potential Parents. Procedia - Social and Behavioral Sciences, 171, 1033-1037.

Lloyd, T.J., \& Hastings, R. (2009). Hope as a psychological resilience factor in mothers and fathers of children with intellectual disabilities. Journal of Intellectual Disability Research, 53, 9657-9968.

Morni, A., \& Sahari, S. (2013). The Impact of Living Environment on Reading Attitudes. Procedia - Social and Behavioral Sciences, 101, 415-425.

Musa, R., Fadzil, M. A., \& Zain, Z. (2007). Translation , validation and psychometric properties of Bahasa Malaysia version of the Depression Anxiety and Stress Scales ( DASS ), 8(2), 82-89.

Noor Amiera Alias, \& Akehsan Dahlan. (2015). Enduring Difficulties: The Challenges of Mothers in Raising Children with Dyslexia. Procedia - Social and Behavioral Sciences, 202(December 2014), 107-114.

Ogston, P. L., Mackintosh, V. H., \& Myers, B. J. (2011). Research in Autism Spectrum Disorders Hope and worry in mothers of children with an autism spectrum disorder or Down syndrome. Research in Autism Spectrum Disorders, 5(4), 1378-1384.

Oprea, C., \& Stan, A. (2012). Mothers of autistic children . How do they feel?, 46, 4191-4194.

Safarzadeh, S. (2012). Connection Hope to Life with Psychology Obstinacy in Scholars Girl and Boy of Islamic Azad University Ahvaz Branch. Procedia - Social and Behavioral Sciences, 46, 1855-1859.

Shabas, S. (2016). Relationships between Parents and Preschool-Age Children Attending Kindergartens. Procedia - Social and Behavioral Sciences, 233(May), 269-273.

Smith, J. A., Flowers, P., \& Larkin, M. (2009). Interpretative phenomenological analysis: Theory, method and research. London: Sage.

Tarhan, S., Bacanli, H., Dombayci, M. A., \& Demir, M. (2011). Quadruple thinking: Hopeful thinking. Procedia - Social and Behavioral Sciences, 12, 568-576.

UNICEF, M. (2014). Children with Disabilities in Malaysia. "Mapping the Policies, Programmes, Interventions and Stakeholders." Convention on The Rights of The Child.

Yujin Kim. (2010). The Pilot Study in Qualitative Inquiry: Identifying issues and learning lessons for culturally competent research. Qualitative Social Work, 10(2), 190-206.

Yurdakal, I. H., \& Kirmizi, F. S. (2015). Elementary Teacher Candidates' Level of Knowledge on Dyslexia (Case of Pamukkale University). Procedia - Social and Behavioral Sciences, 191, 963-968.

Zakeri, H., Jowkar, B., \& Razmjoee, M. (2010). Parenting styles and resilience. Procedia - Social and Behavioral Sciences, 5(2), 1067-1070.

Zarina, Z. A., Zahiruddin, O., \& Che Wan, A. H. (2007). Validation of Malay Mini Mental State Examination. Malaysian Journal of Pscyhiatry, 16(1), 16-19. 
Appendix A. List of the interview guide.

1) Tell me about yourself and your children.

2) Could you share with me about your hope towards your children?

3) Could you share how hopes and expectation affect your providing care to your children?

4) Any others that you would like to share with me 